Sains Malaysiana 50(11)(2021): 3395-3404

http://doi.org/10.17576/jsm-2021-5011-23

\title{
Performance Evaluation of PDMS or PEBAX- Coated Polyetherimide Membrane for Oxygen/Nitrogen Separation
}

(Penilaian Prestasi PDMS atau PEBAX- Bersalut Membran Polieterimida untuk Pemisahan Oksigen/Nitrogen)

\author{
Kok Chung Chong*, Soon Onn Lai, Hui San Thiam, Shee Keat Mah, Woei Jye Lau \& Ahmad Fauzi \\ ISMAIL
}

\begin{abstract}
Since the industrial revolution era, the Earth was suffering from serious air pollution. Millions of people are now suffering from indoor air pollution related diseases, especially in the industrialized countries such as China. One method to improve the indoor air quality is by oxygen enhancement. Membrane technology has been a key research over the past decades due to its low energy usage, minimum chemical consumption as well as small setting up layout. In this study, polyetherimide (PEI) membranes coated with polydimethylsiloxane (PDMS) or poly(ether block amide) (PEBAX) at different concentration (1, 3 or $5 \mathrm{wt} \%)$ were used to evaluate the oxygen/nitrogen gas separation. Prior to the gas permeation study, the membranes were characterized using scanning electron microscope (SEM) for morphology observation and surface elemental analysis by energy dispersive X-ray spectroscope (EDX). The morphology of the selffabricated PEI membranes is composed of a thin and dense structure supported by the finger-like structure. The results obtained from oxygen/nitrogen separation studies shows membrane coated with 3 wt\% PDMS yield a good separation results, exhibiting an improvement of oxygen and nitrogen permeance by $28.2 \%$ and $24.9 \%$, selectivity by $10.4 \%$ (up to 5.08) relative to the base PEI membrane. Meanwhile, the 3 wt\% PEBAX-coated PEI membrane only achieved selectivity of 3.56. The PDMS-coated PEI membrane yield a better separation performance attributed to the fact that PDMS coating on the hollow fiber membrane improve the surface morphology by reducing the defects.
\end{abstract}

Keywords: Gas separation; nitrogen; oxygen; polydimethylsiloxane; polyetherimide; poly(ether block amide)

\section{ABSTRAK}

Sejak era revolusi perindustrian, Bumi mengalami pencemaran udara yang serius. Berjuta-juta orang kini menderita penyakit berkaitan pencemaran udara dalaman, terutamanya mereka yang tinggal di negara perindustrian seperti China. Salah satu kaedah untuk meningkatkan kualiti udara dalaman adalah dengan peningkatan oksigen. Teknologi membran telah menjadi penyelidikan utama selama beberapa dekad yang lalu kerana penggunaan tenaga yang rendah, kadar penggunaan bahan kimia yang minimum dan menggunakan ruang yang kecil. Dalam kajian ini, membran polieterimida (PEI) yang disalut dengan polidimetilsiloksan (PDMS) atau poli(eter blok amida) (PEBAX) pada kepekatan yang berbeza (1, 3 atau 5 wt\%) digunakan untuk menilai pemisahan gas oksigen/nitrogen. Sebelum kajian penelapan gas, membran dicirikan menggunakan mikroskop elektron imbasan (SEM) untuk pemerhatian morfologi dan analisis unsur permukaan dengan spektroskopi sinar-X penyebaran tenaga (EDX). Morfologi membran PEI buatan sendiri terdiri daripada struktur nipis dan padat yang disokong oleh struktur seperti jari. Hasil penyerapan gas menunjukkan bahawa membran yang dilapisi dengan 3\% PDMS adalah membran yang terbaik dengan kadar peningkatan oksigen dan nitrogen sebanyak 28.2\% dan 24.9\% serta peningkatan kepilihan sebanyak 10.4\% (hingga 5.08) berbanding dengan membran PEI yang tidak bersalut. Sementara itu, membran PEI bersalut PEBAX 3\% hanya mencapai kepilihan sebanyak 3.56. Membran PEI yang disalut PDMS menghasilkan prestasi pemisahan yang lebih baik disebabkan oleh fakta bahawa lapisan PDMS dapat memperbaiki morfologi permukaan membran dengan mengurangkan kecacatan.

Kata kunci: Nitrogen; oksigen; pemisahan gas; polieterimida; polidimetilsiloksan; poli(eter blok amida)

\section{INTRODUCTION}

Air pollution is a global phenomenon and it is more severe particularly in the developing countries. Lancet Respiratory Medicine (2012) reported that there are approximately 15 million people suffer from the indoor air pollution related diseases especially those living in cities such as Beijing and Mumbai (Gordon et al. 2017; Zuo et al. 2018). Research had shown that indoor air pollution could negatively 
affect human health as people spend most of the time ( $\sim 80 \%$ ) indoor (Al-Horr et al. 2016; Chong et al. 2017). Poor indoor air quality tends to cause modern diseases such as sick building syndrome and respiratory related diseases. One of the effective ways to combat against these problems is to improve the indoor air quality by oxygen enrichment. Besides this purpose, the process of oxygen enrichment can improve the efficiency of the hypoxemic medical application as well as combustion process in the machines (Baskar \& Senthilkumar 2016; Karar \& Hamdi 2016).

Conventionally, cryogenic distillation and pressure swing adsorption (PSA) are the techniques to produce pure gas. Cryogenic distillation is normally used for large amount of oxygen or nitrogen production which up to 100 tonnes per day (Rackley 2010; Smith \& Klosek 2001). The purity of oxygen and nitrogen gas obtained from this method is in the range of $90-97 \%$ and this method is mainly used in steel making facility and gas supply industry. PSA meanwhile is a medium scale gas production method with an approximate daily production rate of 10-25 tonnes with the purity of $90-93 \%$ (Sircar \& Kratz 1989). It is commonly used as the integration to production systems such as fossil fuel power plant and hospital (Santos et al. 2007). Although both methods are widely used in industry, they are associated with common drawbacks, i.e. high energy intensive and large footprint requirement.

Membrane separation technique is currently an alternative method in oxygen and nitrogen gas production. This technique requires small built-up area and low energy requirement as the membrane itself acts as the barrier for the gas separation (Belaissaoui et al. 2014). Ambient air is pressurized to pass through the membrane and gas molecules are separated according to the membrane permeability and selectivity. The mass transfer in membrane gas separation is depicted by the difference in the pressure between the feed and permeate. As gas separation performance is mainly dependent on the type of membrane material used, it is important to ensure the characteristics of membrane are well designed to cater for the specific gas separation. In gas separation application, the trade-off between permeability and selectivity is crucial for the optimum performance (Sanders et al. 2013). This trade-off is commonly referred as Robeson upper bound where Robeson plotted the upper bound relationship of various binary gas pair separation based on the literature findings (Robeson 2008; Robeson et al. 2015).

The main challenge in gas membrane separation is to yield high selectivity and permeability while maintaining long-term performance stability. Kim et al. (2013) and Wahab et al. (2012) reported that the membrane treated with surface coating commonly possesses better separation efficiency attributed to the coating materials such as zeolite, polydimethylsiloxane (PDMS), graphene oxide or poly(ether block amide) (PEBAX) able to improve the surface defects. Previous studies showed that the PDMS-coated polysulfone (PSF) and polyvinylidene fluoride (PVDF) membrane demonstrated the ability of PDMS coating material to reduce surface defects. Kim et al. (2013) and Liu et al. (2005) on the other hand reported the coating of PEBAX on the PSF and polyacrylonitrile (PAN) flat sheet membrane improve the separation performance of the binary gas pair. Nevertheless, our previous work showed that the PEBAX coating led to an adverse effect on the oxygen/nitrogen gas separation. This is because PEBAX coating tended to stick and bundle the hollow fibers during the membrane dip coating process and reduced its separation efficiency (Chong et al. 2018). Further study on the effect of PEBAX coating on other polymeric membranes is essential to evaluate the effectiveness of the PEBAX coated membrane on the application in gas separation. In this study, the polyetherimide (PEI) hollow fiber membrane was selffabricated by dry-jet wet phase inversion technique. The shell side of the hollow fiber membrane was coated with either PDMS or PEBAX materials to evaluate the effects of the coating materials on the oxygen/nitrogen binary gas pair separation. The properties of the membrane were carefully examined by instrumental characterization before undergoing the gas permeation study.

\section{MATERIALS}

The polymeric material used in this study is polyetherimide (PEI) with the purity more than 98\% obtained from Merck Darmstadt, Germany. The main solvent, N,N- dimethyl-acetamide (DMAc, > 99.5\%) and co-solvent ethanol, (EtOH, >99\%) obtained from SigmaAldrich, Missouri, United States were used to prepare the PEI dope solution. Another co-solvent used in the membrane dope solution, tetrahydrofuran (THF, >99.5\%) was purchased from QReC, Selangor, Malaysia. In this study, polydimethylsiloxane (PDMS, > 98\%) and polyether block amide (PEBAX, >95\%) obtained from Sigma-Aldrich, Missouri, United States and Arkema, Pennsylvania, United States, respectively, were used as the coating materials for the fabricated membrane.

\section{PREPARATION OF POLYMERIC HOLLOW FIBER MEMBRANE}

The PEI pellet was dry in oven at $70{ }^{\circ} \mathrm{C}$ for a day to prior to use in order to remove any moisture residue. The dope 
solution that composed of $30 \mathrm{wt} \%$ PEI, $30 \mathrm{wt} \%$ DMAc, $30 \mathrm{wt} \%$ THF and $10 \mathrm{wt} \%$ EtOH was slowly mixed and stirred by an overhead stirrer to obtain a homogenous dope solution. The dope solution was then place in an ultrasonic sonication for $8 \mathrm{~h}$ to remove any bubble residues before the spinning process. The hollow fiber membrane in this study were produced by the phase inversion method which schematically illustrated in Figure 1. The membrane dope solution was firstly fed to the reservoir and the solution was later transferred to the spinneret via gear pump. The bore fluid consisted of distilled water flew through the inner bore of the spinneret with the assist of syringe pump. The solvent/non-solvent exchange process occurred in the spinneret where the bore fluid removes the solvent from the dope solution, forming the lumen of the hollow fiber membrane. Nascent membrane was formed when the fiber was immersed into the coagulation bath whereby the solvent was removed by the water in the bath. The solvent in the nascent membrane was further eliminated in the washing bath. Lastly, the hollow fiber membrane was collected by the windup drum. The detailed spinning parameters for hollow fiber fabrication are tabulated in Table 1.

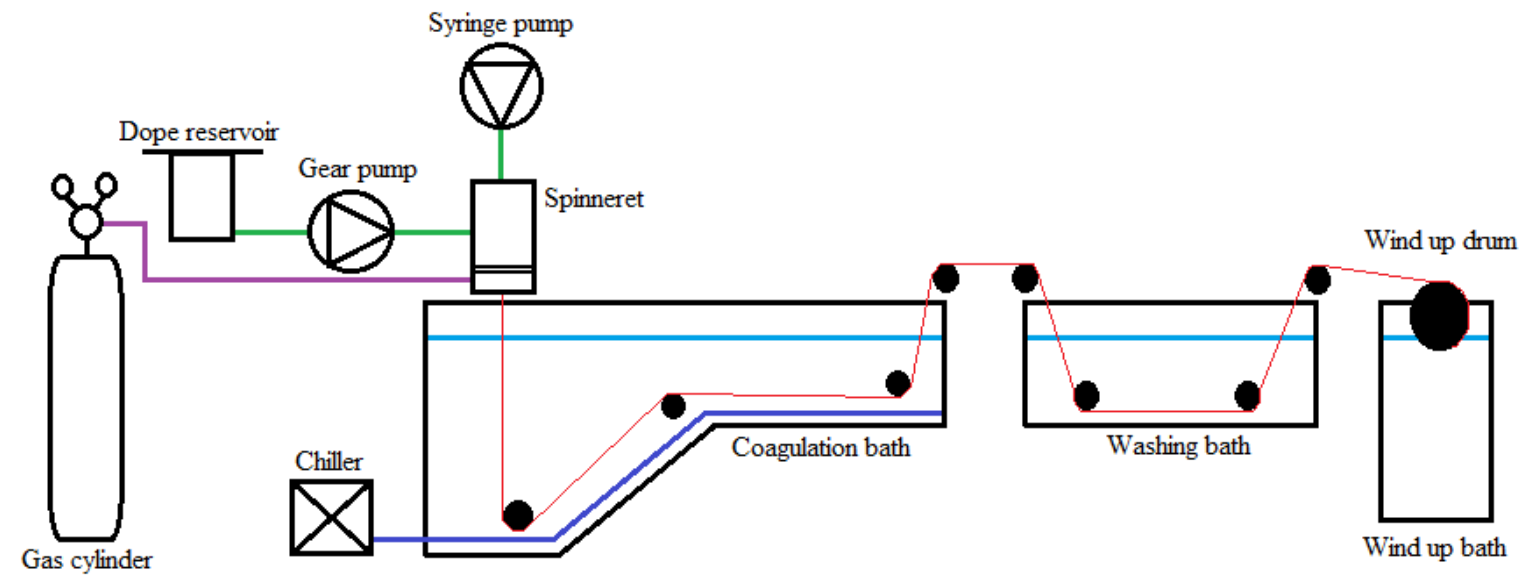

FIGURE 1. Schematic diagram for PEI hollow fiber membrane fabrication method

TABLE 1. PEI hollow fiber membrane fabrication parameter

\begin{tabular}{lc}
\hline Spinning parameter & Value \\
\hline Spinneret OD/ID $(\mathrm{mm} / \mathrm{mm})$ & $0.6 / 0.3$ \\
Bore liquid & Distilled water \\
Bore liquid temperature $\left({ }^{\circ} \mathrm{C}\right)$ & 25 \\
Bore liquid flow rate $(\mathrm{mL} / \mathrm{min})$ & 0.3 \\
External coagulant & Tap water \\
External coagulant temperature $\left({ }^{\circ} \mathrm{C}\right)$ & 25 \\
Air gap (cm) & 30 \\
Room relative humidity $(\%)$ & $55 \pm 5$ \\
\hline
\end{tabular}




\section{COATING OF MEMBRANE SURFACE}

The outer surface PEI membranes were dip coated with either PDMS or PEBAX solution. The coating concentration of $1 \mathrm{wt} \%, 3 \mathrm{wt} \%$, and $5 \mathrm{wt} \%$ was studied to evaluate the effect of coating on the oxygen/nitrogen separation. The PDMS coating solution was prepared by blending the $n$-hexane solution into the PDMS base under the pre-defined volume to acquire the desired concentration. The mixed solution was stirred by magnetic stirrer for $2 \mathrm{~h}$ under the room temperature to obtain homogenous solution. The solution was then sonicated in an ultrasonic bath for $4 \mathrm{~h}$ to remove unwanted microbubbles formed during the stirring process. The coating method employed in this study was the dip coating method. PEI hollow fiber membranes were dipped and fully immersed into the coating solution. After 5 min, the hollow fiber membranes were taken out from the coating solution and the extra coating solution on the membrane was drained off before heating. The hollow fiber membranes were dried in the vacuum oven at $70^{\circ} \mathrm{C}$ for $4 \mathrm{~h}$. The dip coating process were repeated for five times to ensure perfect coating layer was formed on the membrane surface.

The preparation protocol of PDMS or PEBAX coating solution is similar and it was prepared in two steps. The mass coating materials in pellet form were measured by an electronic weight balance follow by mixing with ethanol and water at the ratio of 30 to 70 . The solution was stirred at room temperature for $4 \mathrm{~h}$ follow by degassing for $4 \mathrm{~h}$ by ultrasonic sonicator. This protocol was then repeated for the preparation of different PDMS or PEBAX coating concentration. The hollow fiber membranes were dip coated into the coating solution for five times to ensure a good coating layer. Nevertheless, it is noteworthy to mention that extra attention is needed on the curing of the PEBAX coated membrane by separating each of the fibers in vacuum oven. This is because fibers tend to stick and bundled together due to the adhesive nature of PEBAX.

\section{MEMBRANE CHARACTERIZATIONS}

Scanning electron microscope (SEM) from Hitachi, Japan (Model: S-3400N) was utilized to observe the surface morphology and cross section of the hollow fiber membrane. The hollow fiber was undergoing pretreatment where it was fractured cryogenically with liquid nitrogen to obtain a clear cross section image for a better illustration of membrane morphology. Then, the hollow fiber membranes were coated with a layer of platinum by sputter coating machine (Emitech, SC7620) to improve the surface conductivity. At different magnifications, the micrographs of surfaces at both the shell side and cross section were obtained. The elementary analysis on the membrane surface was performed using energy dispersive X-ray (EDX) spectrometer. The EDX characterization was repeated for at least five times at different locations on the surface to obtain average results on the atomic percentage.

\section{GAS PERMEATION STUDY}

The setup of the permeation system is exhibit in Figure 2. Five hollow fiber membranes are inserted into stainless steel membrane module and epoxy resin was applied to seal the hollow fiber membrane at the dead end. Additionally, the arrangement of flow is shell side feed pattern where the feed gas from cylinder diffuses across the hollow fiber membrane outer surface and permeate gas will flow over

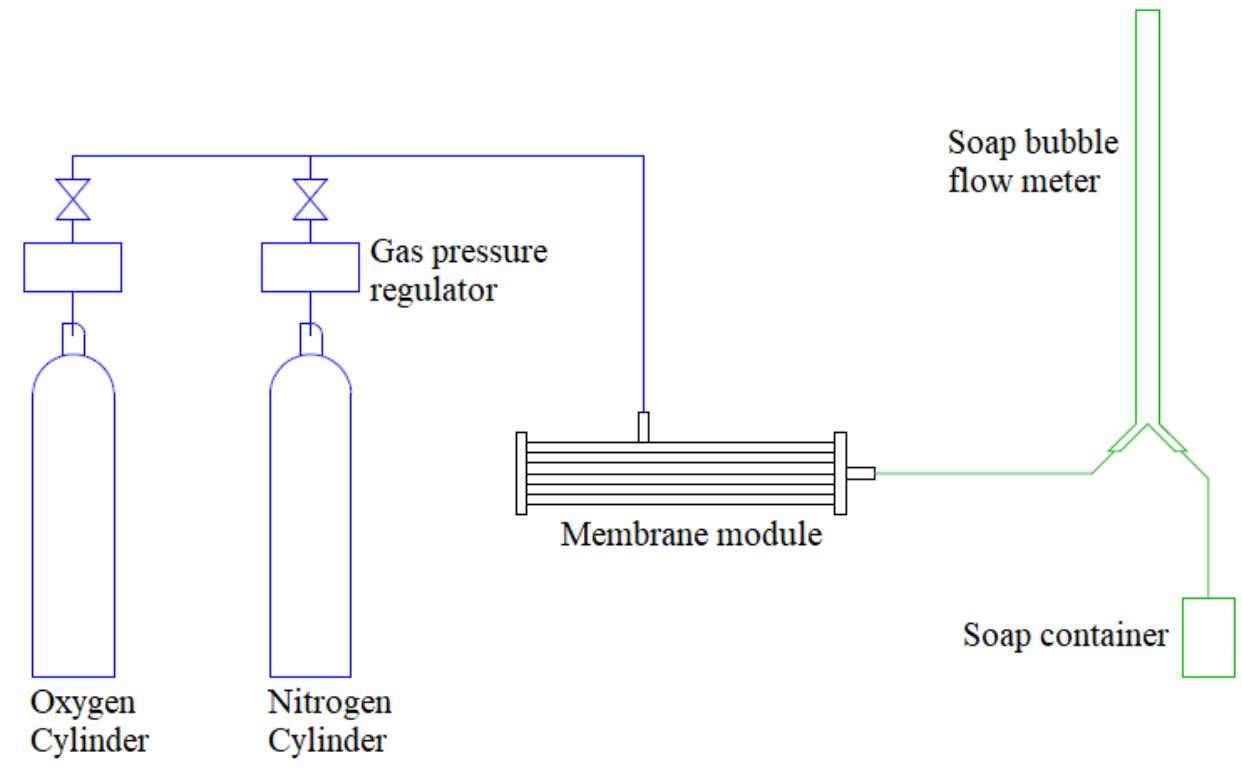

FIGURE 2. Setting up of permeation study (Chong et al. 2018) 
the lumen of fiber. The experiment was carried out at the room temperature and the pressure was fixed at 5 bars. The experiment was repeated five times in order to ensure reproducibility.

\section{RESULTS AND DISCUSSION}

\section{MORPHOLOGY OF HOLLOW FIBER MEMBRANE}

The cross-sectional morphology of the pristine PEI membrane is shown in Figure 3. As can be seen, the membrane inner layer is made up of thin and dense structure supported by finger-like structure. This morphology is the typical structure of asymmetric membrane obtained from the phase inversion process (Chong et al. 2014; Khayet et al. 2009). The thin skin layer can offer gas separation while the porous structure allows the gas molecules to permeate easily. During phase separation, two phases are developed: polymer-rich and polymer-lean. The fingerlike structure is initiated by polymer-lean phase nuclei and created under the top layer. The growth of these nuclei is maintained if the solvent supplied are sufficient and ends

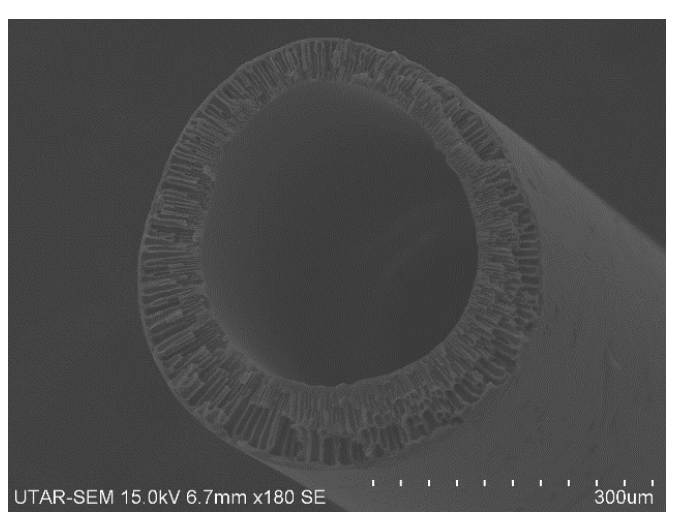

(a)

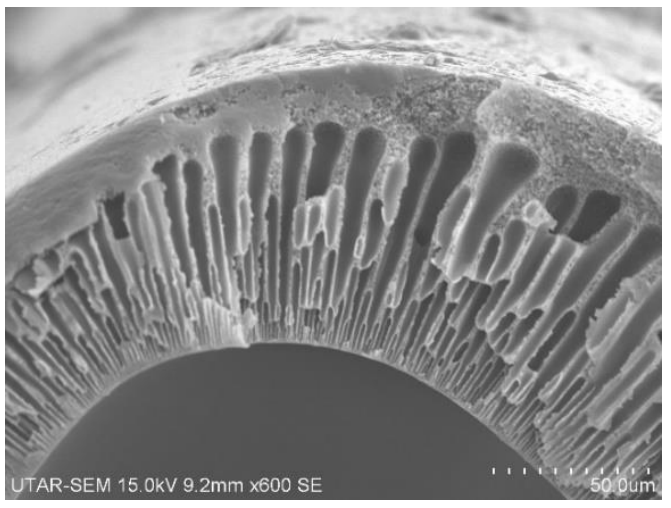

(b)

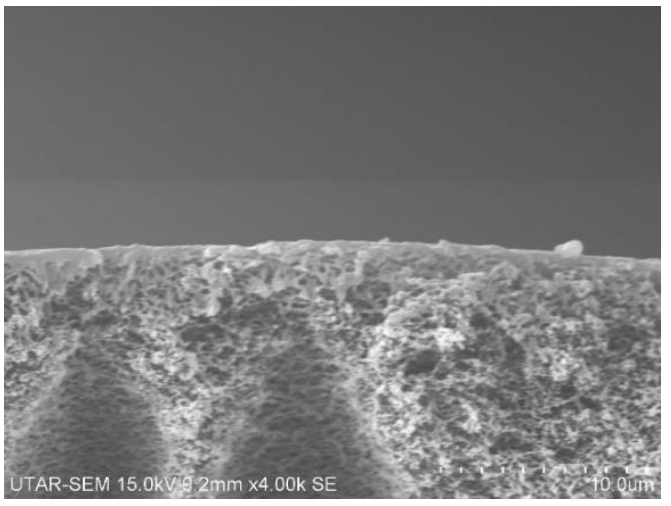

(c)

FIGURE 3. Morphology uncoated PEI membrane, (a) cross section, (b) membrane thickness and (c) skin layer 
when initiation of new nuclei occurs. The termination of growth can also occur at glass transition temperature for polymer-lean phase (Zhou et al. 2018). With the application of water which is a relatively strong non-solvent for both bore fluid and coagulation bath, the solvent/non-solvent exchange occurs aggressively forming the finger like structure (Moaddeb \& Koros 1997).
EFFECTS OF PDMS AND PEBAX COATING ON MEMBRANE SURFACE

Figure 4 compares the top surface of PDMS and PEBAXcoated PEI hollow fiber membranes. The images showed the extra layer of PDMS or PEBAX was formed on the shell side of the hollow fiber membranes in which the coating

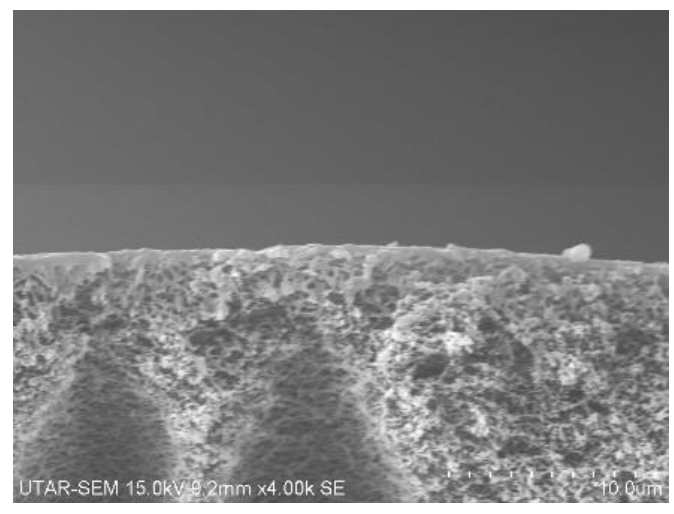

(a)

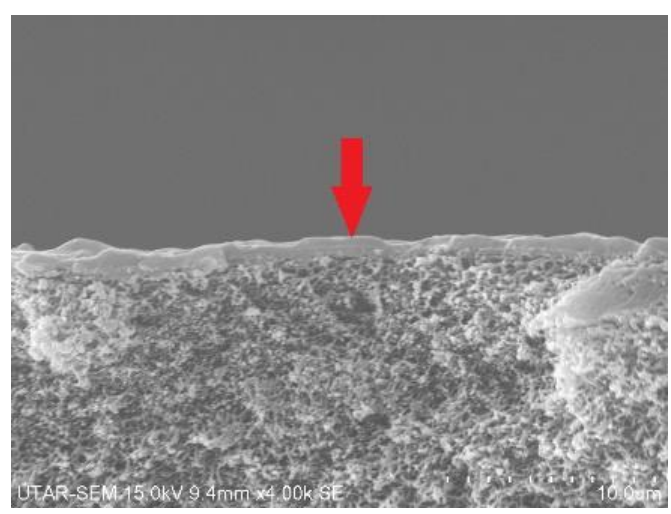

(b)

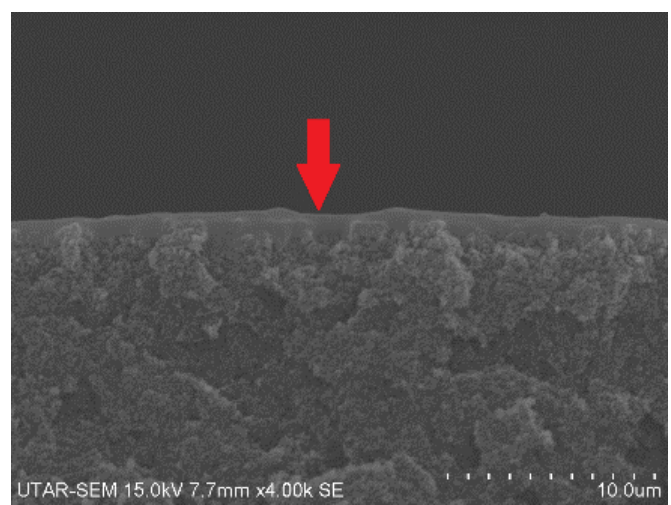

(c)

FIGURE 4. Morphology of PEI membrane outer layer, (a) $1 \mathrm{wt} \%$ PDMS coating, (b) $3 \mathrm{wt} \%$ PDMS coating and (c) $3 \mathrm{wt} \%$ PEBAX coating 
thickness increased with increasing coating solution concentration. The coating layer was increased from 1.08 to $3.54 \mu \mathrm{m}$ and from 1.29 to $3.86 \mu \mathrm{m}$, respectively, for PDMS and PEBAX coating, respectively, as tabulated in Table 2. The trends observed in this work is similar to our previous study in which the coating thickness increases with the concentration of the coating materials used. However, it is noteworthy to mention that the coating thickness of PEBAX are generally higher than that of PDMS coating. This phenomenon was reported by Esposito et al. (2015) and Wang et al. (2014) where the PEBAX solution has a lower viscosity compared to PDMS solution leading to rapid gelation on the membrane surface.

TABLE 2. Coating thickness for the as spun hollow fiber membranes

\begin{tabular}{lc}
\hline Membrane & Thickness $(\mu \mathrm{m})$ \\
\hline PEI-1PDMS & $1.08 \pm 0.12$ \\
PEI-3PDMS & $2.13 \pm 0.19$ \\
PEI-5PDMS & $3.54 \pm 0.22$ \\
PEI-1PEBAX & $1.29 \pm 0.17$ \\
PEI-3PEBAX & $2.51 \pm 0.28$ \\
PEI-5PEBAX & $3.86 \pm 0.33$
\end{tabular}

\section{ELEMENTAL ANALYSIS OF MEMBRANE SURFACE CHEMISTRY}

The results of elementary analysis conducted by EDX on membrane surface are tabulated in Table 3 . The chemical formula for the PEI polymeric materials is $\left(\mathrm{C}_{39} \mathrm{H}_{30} \mathrm{~N}_{2} \mathrm{O}_{6}\right) \mathrm{n}$ which consists of carbon, hydrogen, nitrogen, and oxygen (Wang et al. 1998). The detection of these elements in the uncoated membrane reflected the successful fabrication of the PEI hollow fiber membrane in this study with the composition of materials used (Rezaei et al. 2015). With the use of the coating materials, the presence of new elements or the increase in elemental composition were observed. Silicon was found on the membrane surface coated with PDMS, indicating the PDMS was successfully coated on the surface. The percentage of silicon element increased with the increase of the PDMS coating concentration and these findings are similar to our previous work (Chong et al. 2018). Comparable to the PDMS coated membrane, the nitrogen concentration for PEBAX coated materials increased with the increment of the coating concentration. The increase in the percentage of nitrogen elements in the PEBAX coated membrane was attributed to the content of the nitrogen in the PEBAX molecular chain.

TABLE 3. Elementary analysis on membrane surface

\begin{tabular}{|c|c|c|c|c|}
\hline \multirow{2}{*}{ Membrane } & \multicolumn{3}{|c|}{ Trace element (At.\%) } & \multirow[b]{2}{*}{ Nitrogen $(\mathrm{N})$} \\
\hline & Carbon (C) & Oxygen $(\mathrm{O})$ & Silicon (Si) & \\
\hline PEI & $83.58 \pm 4.78$ & $16.42 \pm 0.94$ & Not detected & Not detected \\
\hline PEI-1PDMS & $82.31 \pm 4.59$ & $15.26 \pm 0.74$ & $2.43 \pm 0.13$ & Not detected \\
\hline PEI-3PDMS & $80.94 \pm 4.92$ & $15.34 \pm 0.69$ & $3.72 \pm 0.19$ & Not detected \\
\hline PEI-5PDMS & $79.65 \pm 4.07$ & $15.42 \pm 0.71$ & $4.93 \pm 0.22$ & Not detected \\
\hline PEI-1PEBAX & $81.42 \pm 4.52$ & $15.46 \pm 0.65$ & Not detected & $3.12 \pm 0.16$ \\
\hline PEI-3PEBAX & $80.17 \pm 4.13$ & $14.92 \pm 0.57$ & Not detected & $4.91 \pm 0.24$ \\
\hline PEI-5PEBAX & $78.84 \pm 3.41$ & $14.80 \pm 0.61$ & Not detected & $6.36 \pm 0.52$ \\
\hline
\end{tabular}


GAS PERMEATION PERFORMANCE OF PRISTINE AND COATED PEI MEMBRANE

The binary gas separation performance in terms of the gas permeance and selectivity is presented in Figure 5(a) and 5(b), respectively. The gas permeance performance recorded in this study is in the range of 24-49 GPU and 7-10 GPU for oxygen and nitrogen gas, respectively. The uncoated PEI membrane recorded 35.52 and 7.79 GPU for the permeance of oxygen and nitrogen gas, respectively. Based on the gas permeation results obtained, it was found that the PDMS coating generally recorded a better permeance results whereas permeance for PEBAX coating showed a downward pattern.

The membranes coated with PDMS generally recorded a better result in permeance in relative to the uncoated membrane. The membrane coated with 3 $w t \%$ PDMS exhibited the gas permeance of 49.51 and $9.73 \mathrm{GPU}$, for oxygen and nitrogen gas, respectively, which corresponded to an enhancement of $28.2 \%$ and $24.9 \%$, respectively. The results obtained from the

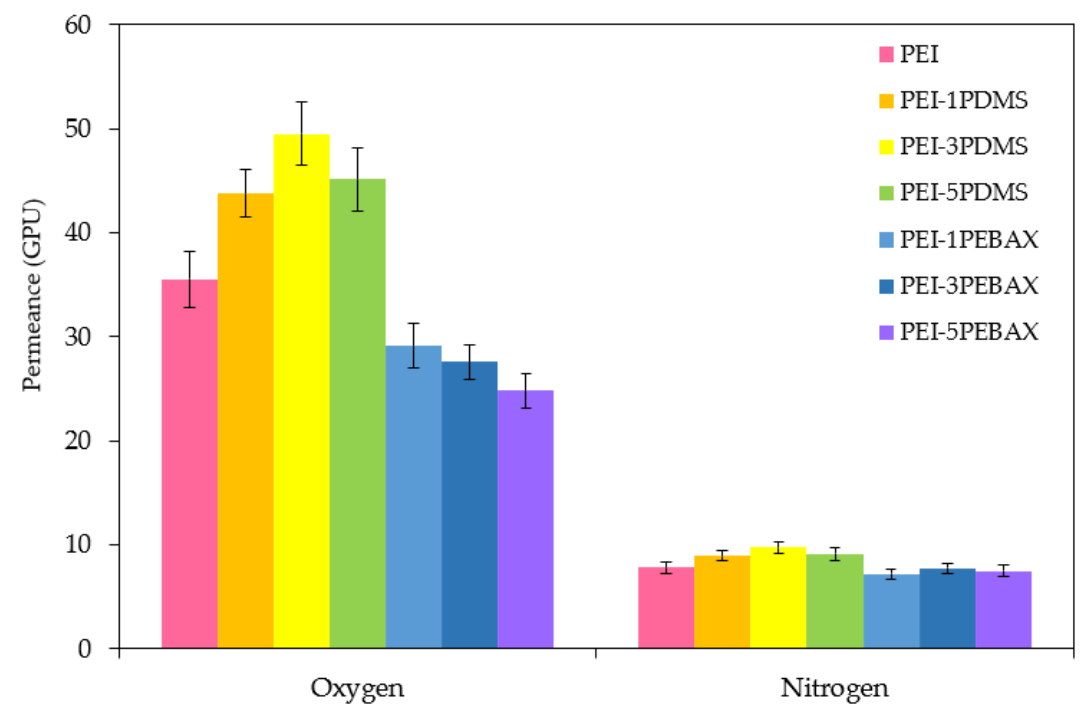

(a)

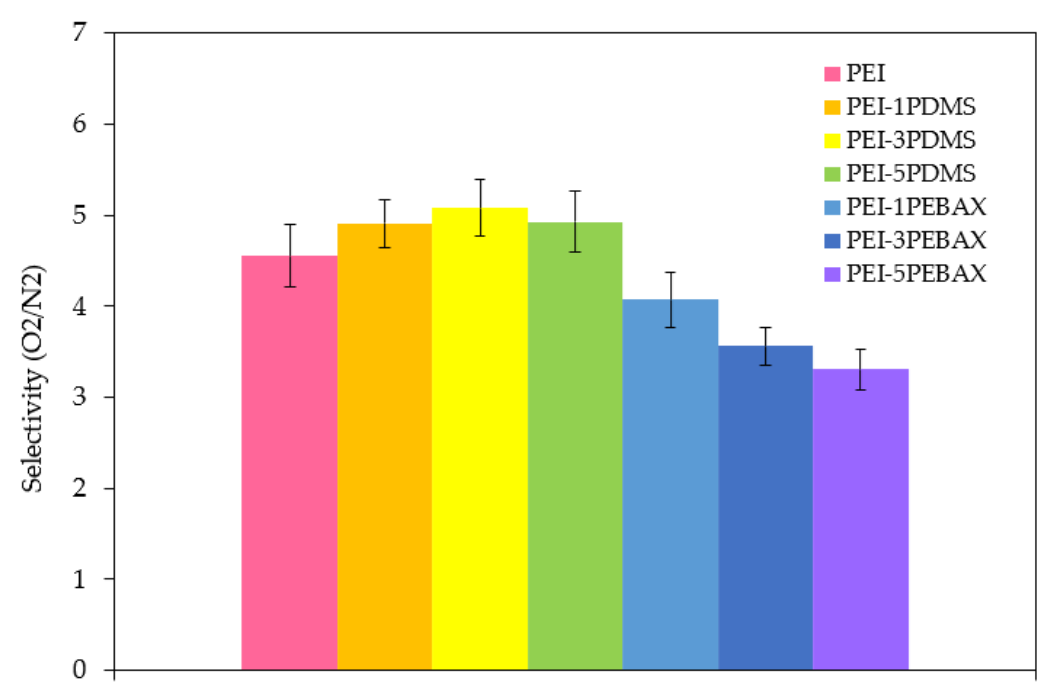

(b)

FIGURE 5. Oxigen/nitrogen separation performance, (a) permeance (x 10-6 $\mathrm{cm}_{3}$ $\mathrm{STP} / \mathrm{cm}_{2} \mathrm{~s} \mathrm{~cm} \mathrm{Hg}(\mathrm{GPU})$ ), and (b) selectivity 
PDMS coating agree with the literature report where the addition of PDMS coating on the membrane surface is able to enhance the gas separation performance. This phenomenon is due to the fact that PDMS coating is able to improve the membrane surface morphology by reducing the defects. In addition, the high affinity of PDMS materials towards oxygen molecules tended to enhance the permeance. Nevertheless, with the increase in the concentration of the PDMS solution, the gas permeance tended to decrease as a result of the increased resistivity of the hollow fiber membrane following increase in coating thickness (Khalilinejad et al. 2015; Moradi et al. 2017). On the other hand, the application of the PEBAX coating on the PEI hollow fiber membrane generally shows a reducing pattern on both the oxygen and nitrogen permeance. The nature of PEBAX coating has a lower affinity towards non-polar molecule such as oxygen gas, lead to a lower gas permeance (Pokhrel et al. 2018). This finding is similar to the report by Wang (2000) as the PEBAX coating experienced a rapid gelation when it was applied on the membrane surface. Analogous results were reported by Jamil et al. (2020) where the rapid gelation of the PEBAX coating on the membrane surface lead to a poor homogenous and superior integrity, leading to lower gas permeance and selectivity. Consequently, the hollow fiber tends to get together attributed to the rapid gelation of the PEBAX solution or the fiber stuck into bundle during curing process. In order to overcome this drawback, the coating of the hollow fiber was done individually instead of bundle to obtain the best coating result.

\section{CONCLUSION}

In this work, the hollow fiber membrane was successfully fabricated by dry-jet wet phase inversion method using dope solution composed of PEI, DMAc, THC, and ethanol. The hollow fiber membrane was coated by PDMS or PEBAX at different coating concentration. The gas permeation results suggested that PDMS-coated PEI membrane yielded better separation performance of oxygen/nitrogen in terms of permeance and selectivity compared to the PEBAX-coated and uncoated PEI membrane. The PEI membrane coated with $3 \mathrm{wt} \%$ PDMS exhibited the best performance, recording permeance of 49.51 and 9.73 GPU for oxygen and nitrogen, respectively. This resulted in gas pair selectivity of 5.08. The results of PEBAX-coated PEI membranes generally possessed lower gas permeance and selectivity than those of the pristine and PDMScoated membranes. The lower performance of the
PEBAX-coated membrane was attributed to high degree of adhesion during the membrane dip coating process that led to the reduction of effective surface area.

\section{ACKNOWLEDGEMENTS}

The authors would like to thank Mayair Manufacturing (M) Sdn. Bhd. for the sponsorship of this work under the Studentship Research Grant (Grant no: 4464/000).

\section{REFERENCES}

Al-Horr, Y., Arif, M., Katafygiotou, M., Mazroei, A., Kaushik, A. \& Elsarrag, E. 2016. Impact of indoor environmental quality on occupant well-being and comfort: A review of the literature. International Journal of Sustainability Built Environment 5(1): 1-11.

Baskar, P. \& Senthilkumar, A. 2016. Effects of oxygen enriched combustion on pollution and performance characteristics of a diesel engine. International Journal of Science and Technology 19(1): 438-443.

Belaissaoui, B., Le Moullec, Y., Hagi, H. \& Favre, E. 2014. Energy efficiency of oxygen enriched air production technologies: Cryogeny vs membranes. Energy Procedia 63: 497-503.

Chong, K.C., Lai, S.O., Lau, W.J., Thiam, H.S., Ismail, A.F. \& Roslan, R.R. 2018. Preparation, characterization, and performance evaluation of polysulfone hollow fiber membrane with PEBAX or PDMS coating for oxygen enhancement process. Polymers 10(2): 126.

Chong, K.C., Lai, S.O., Lau, W.J., Thiam, H.S., Ismail, A.F. \& Zulhairun, A.K. 2017. Fabrication and characterization of polysulfone membranes coated with polydimethysiloxane for oxygen enrichment. Aerosol Air Quality Research 17(11): 2735-2742.

Chong, K.C., Lai, S.O., Lee, K.M., Lau, W.J., Ismail, A.F. \& Ooi, B.S. 2014. Characteristic and performance of polyvinylidene fluoride membranes blended with different additives in direct contact membrane distillation. Desalination Water Treatment 54(12): 3218-3226.

Esposito, E., Clarizia, G., Bernardo, P., Jansen, J., Sedláková, Z. \& Izák, P. 2015. Pebax®/PAN hollow fiber membranes for $\mathrm{CO}_{2} / \mathrm{CH}_{4}$ separation. Chemical Engineering Process 94 : 53-61.

Gordon, S., Mortimer, K., Grigg, J. \& Balmes, J. 2017. In control of ambient and household air pollution - how low should we go? Lancet Respiratory Medicine 17: 1-2.

Jamil, N., Othman, N.H., Shahrudin, M.Z., Razlan, M.R.M., Alias, N.H., Marpani, F., Lau, W.J., Goh, P.S. \& Ismail, A.F. 2020. Effects of PEBAX coating concentrations on $\mathrm{CO}_{2} / \mathrm{CH}_{4}$ separation of RGO/ZIF-8 PES membranes. Jurnal Teknologi 82(2): 51-60.

Karar, H.W. \& Hamdi, A. 2016. Analysis of the factors that affect medical oxygen demand an empirical study at government Hospitals in Khartoum State. IOSR Journal of Mathematics 12: $22-26$. 
Khalilinejad, I., Sanaeepur, H. \& Kargari, A. 2015. Preparation of poly(ether-6-block amide)/PVC thin film composite membrane for $\mathrm{CO}_{2}$ separation: Effect of top layer thickness and operating parameters. Journal of Membrane Science Research 1: 124-129.

Khayet, M., García-Payo, M., Qusay, F. \& Zubaidy, M. 2009. Structural and performance studies of poly(vinyl chloride) hollow fiber membranes prepared at different air gap lengths. Journal of Membrane Science 330(1-2): 30-39.

Kim, K., Ingole, P., Kim, J. \& Lee, H. 2013. Separation performance of PEBAX/PEI hollow fiber composite membrane for $\mathrm{SO}_{2} / \mathrm{CO}_{2} / \mathrm{N}_{2}$ mixed gas. Chemical Engineering Journal 233: 242-250.

Liu, L., Chakma, A. \& Feng, X. 2005. $\mathrm{CO}_{2} / \mathrm{N}_{2}$ separation by poly(ether block amide) thin film hollow fiber composite membranes. Industrial \& Engineering Chemical Research 44(17): 6874-6882.

Moaddeb, M. \& Koros, W. 1997. Occlusion of pores of polymeric membranes with colloidal silica. Journal of Membrane Science 136(1-2): 273-277.

Moradi, M., Pourafshari, C.M., Noie, S., Hesampour, M. \& Mänttäri, M. 2017. PDMS coating of used TFCRO membranes for $\mathrm{O}_{2} / \mathrm{N}_{2}$ and $\mathrm{CO}_{2} / \mathrm{N}_{2}$ gas separation applications. Polymer Testing 63: 101-109.

Pokhrel, J., Bhoria, N., Anastasiou, S., Tsoufis, T., Gournis, D., Romanos, G. \& Karanikolos, N. 2018. $\mathrm{CO}_{2}$ adsorption behavior of amine-functionalized ZIF-8, graphene oxide, and ZIF-8/graphene oxide composites under dry and wet conditions. Microporous and Mesoporous Materials 267: 53-67.

Rackley, S.A. 2010. Carbon Capture and Storage. 1st ed. Massachusetts: Butterworth-Heinemann.

Rezaei, A.M., Ismail, A.F., Matsuura, T., Ng, B. \& Abdullah, M. 2015. Fabrication and characterization of porous polyetherimide/montmorillonite hollow fiber mixed matrix membranes for $\mathrm{CO}_{2}$ absorption via membrane contactor. Chemical Engineering Journal 269: 51-59.

Robeson, L. 2008. The upper bound revisited. Journal of Membrane Science 320(1-2): 390-400.

Robeson, L., Liu, Q., Freeman, B. \& Paul, D. 2015. Comparison of transport properties of rubbery and glassy polymers and the relevance to the upper bound relationship. Journal of Membrane Science 476: 421-431.

Sanders, D., Smith, Z., Guo, R., Robeson, L., McGrath, J. \& Paul, D. 2013. Energy-efficient polymeric gas separation membranes for a sustainable future: A review. Polymer 54(18): 4729-4761.

Santos, J., Cruz, P., Regala, T., Magalhães, F. \& Mendes, A. 2007. High-purity oxygen production by pressure swing adsorption. Industrial \& Engineering Chemistry Research 46(2): 591-599.
Sircar, S. \& Kratz, W. 1989. Oxygen production by pressure swing adsorption. Separation Science and Technology 24(56): 429-440.

Smith, A. \& Klosek, J. 2001. A review of air separation technologies and their integration with energy conversion processes. Fuel Process Technology 70(2): 115-134.

Wahab, M., Ismail, A.F. \& Shilton, S. 2012. Studies on gas permeation performance of asymmetric polysulfone hollow fiber mixed matrix membranes using nanosized fumed silica as fillers. Separation and Purification Technology 86: 41-48.

Wang, D. 2000. Porous PVDF asymmetric hollow fiber membranes prepared with the use of small molecular additives. Journal of Membrane Science 178(1-2): 13-23.

Wang, D., Li, K. \& Teo, W. 1998. Preparation and characterization of polyetherimide asymmetric hollow fiber membranes for gas separation. Journal of Membrane Science 138(2): 193-201.

Wang, L., Li, Y., Li, S., Ji, P. \& Jiang, C. 2014. Preparation of composite poly(ether block amide) membrane for $\mathrm{CO}_{2}$ capture. Journal of Energy Chemistry 23(6): 717-725.

Zhou, Y., Chen, W., Wang, P. \& Zhang, Y. 2018. Dense and thin $13 \mathrm{X}$ membranes on porous $\alpha-\mathrm{Al}_{2} \mathrm{O}_{3}$ tubes: Preparation, structure and deep purification of oxygenated compounds from gaseous olefin flow. RSC Advance 8(25): 1372813738.

Zuo, J., Ji, W., Ben, Y., Hassan, M., Fan, W. \& Bates, L. 2018. Using big data from air quality monitors to evaluate indoor $\mathrm{PM}_{2.5}$ exposure in buildings: Case study in Beijing. Environmental Pollution 240: 839-847.

Kok Chung Chong*, Soon Onn Lai, Hui San Thiam \& Shee Keat Mah

Department of Chemical Engineering

Lee Kong Chian Faculty of Engineering and Science

Universiti Tunku Abdul Rahman

Jalan Sungai Long, Bandar Sungai Long

Cheras, 43000 Kajang, Selangor Darul Ehsan

Malaysia

Woei Jye Lau \& Ahmad Fauzi Ismail

Advanced Membrane Technology Research Centre (AMTEC)

Universiti Teknologi Malaysia

81310 Skudai, Johor Darul Takzim

Malaysia

*Corresponding author; email: chongkc@utar.edu.my

Received: 25 May 2020

Accepted: 8 March 2021 